\title{
Spontaneous Quantal Transmitter Secretion from Myocytes and Fibroblasts: Comparison with Neuronal Secretion
}

\author{
Romaln GIrod, Sergey Popov, Janet Alder, James Q. Zheng, Ann Lohof, and Mu-ming Poo \\ Department of Biological Sciences, Columbia University, New York, New York 10027
}

When exogenous ACh is loaded into the cytoplasm of cultured amphibian myocytes and fibroblasts, the cells undergo spontaneous quantal $\mathrm{ACh}$ secretion, as detected by the appearance of pulsatile membrane currents in Xenopus myocytes which are manipulated into contact with the cells. These currents resemble in many ways the miniature endplate currents (MEPCs) observed at developing neuromuscular synapses formed on these Xenopus myocytes. Analyses of the frequency, amplitude, and time course of these currents suggests similarity in the cellular mechanisms involved in the packaging and secretion of $\mathrm{ACh}$ quanta in fibroblasts, myocytes, and developing neurons. The size of the ACh packets released by the non-neuronal cells were found to be very similar to the size of the neuronal ACh quanta, which are thought to result from the exocytotic release of synaptic vesicles. Moreover, the kinetics with which the ACh packets are discharged from all three cell types are comparable, although the speed of secretion in non-neuronal cells is somewhat slower and more irregular. The spontaneous quantal $\mathrm{ACh}$ secretion from neurons and myocytes was decreased by reducing cytosolic $\mathrm{Ca}^{21}$ level and enhanced by activation of protein kinase $\mathbf{C}$ with phorbol ester, but secretion from fibroblasts was unaffected by both treatments. The spontaneous secretion from fibroblasts did show some sensitivity to a rise in cytosolic $\mathrm{Ca}^{2+}$ after treatment with a $\mathrm{Ca}^{2+}$ ionophore. These observations support the hypothesis that the basic machinery for transmitter secretion operating in neurons derive from a more ubiquitous mechanism used for constitutive secretion and membrane trafficking in non-neuronal cells, and neuronal differentiation involves expression of additional unique components for the regulation of the spontaneous quantal secretion.

[Key words: quantal secretion, ACh, cell cultures, fibroblast, myocyte, Xenopus, synaptic transmission]

The neurotransmitter $\mathrm{ACh}$ is released at the neuromuscular junction (Del Castillo and Katz, 1954) and at the Torpedo electric organ (Dunant and Muller, 1986) in the form of multimolecular packets, or quanta. The number of $\mathrm{ACh}$ molccules containcd in a single quantum has been estimated to be $7000-10,000$, both at the endplate (Kuffler and Yoshikami, 1975) and in the electric

Received June 16, 1994; revised Oct. 4, 1994; accepted Oct. 20, 1994

We thank M. Jackson for helpful suggestions. This work was supported by grants from the National Institutes of Health (NS 22764, NS31923) to M.-m.P. and from the Swiss FNRS (823A-033357) to R.G.

Correspondence should be addressed to Dr. M.-m. Poo at the above address. Copyright (C) 1995 Society for Neuroscience $0270-6474 / 95 / 152826-13 \$ 05.00 / 0$ organ (Dunant and Muller, 1986). In developing neuromuscular junctions the quantal size varies over a wide range, resulting in a skewed distribution of miniature endplate currents (MEPCs) detected in the postsynaptic muscle cell (Muniak et al., 1982; Kidokoro, 1984; Evers et al., 1989). This property of quantal ACh secretion has been shown to be maintained in isolated nerve terminals known as synaptosomes (Girod et al., 1992).

It is generally believed that quantal $\Lambda \mathrm{Ch}$ secretion reflects the exocytosis of ACh-containing synaptic vesicles, organelles unique to nerve terminals. However, Dan and Poo (1992) showed that isolated myocytes loaded with $10-30 \mathrm{~mm}$ ACh in the cytoplasm (via a whole-cell recording pipette) secrete $\mathrm{ACh}$ spontaneously in a pulsatile manner reminiscent of quantal secretion by nerve terminals. This quantal secretion by the AChloaded myocyte resulted in the activation of the myocyte's own ACh receptors and subsequent appearance of spontaneous membrane currents that resemble MFPC.s. In the present study, we found that injection of $\mathrm{ACh}$ into the cytoplasm of amphibian fibroblasts also led to quantal ACh secretion from the fibroblasts, as detected by a myocyte manipulated into contact. Pharmacological evidence suggests that the MEPCs-like events detected at the surface of ACh-loaded myocytes or fibroblasts reflect exocytotic secretion of $\mathrm{ACh}$-containing vesicles. These findings raise several immediate questions. How similar are these exocytotic secretion events to those observed at presynaptic nerve terminals? Is quantal $\mathrm{ACh}$ secretion from non-neuronal cells regulated in the same fashion as in neurons? Are synaptic vesicles derived from a regulated secretion pathway existing in all cell types? What roles do nerve-terminal specific components play in quantal transmitter secretion? In order to address these questions, quantitative comparison of the propertics of quantal sccretion events from neurons, myocytes, and fibroblasts is required. In the present study, we first analyzed in detail the frequency, amplitude and time course of quantal secretion from neurons, myocytes, and fibroblasts. We then focused our attention on the regulation of quantal $\mathrm{ACh}$ secretion in these three cell types by cytosolic $\mathrm{Ca}^{2+}$ concentration and by the addition of a protein kinase $C$ activator. The results of these studies provide a basis for further understanding of regulated exocytosis in non-neuronal cells and of the differentiation of the quantal transmitter secretion mechanism in neurons.

Portions of this work have been published previously in abstract form (Alder et al., 1993; Girod et al., 1993b).

\section{Materials and Methods}

Cell cultures and chemicals. Xenopus nerve-muscle cultures were prepared as previously reported (Spitzer and Lamborghini, 1976; Anderson et al., 1977; Tabti and Poo, 1991). Briefly, the neural tube and the associated myotomal tissue of $1 \mathrm{~d}$ old Xenopus embryos (stage 20-22, 
Nieuwkoop and Faber, 1967) were dissociated in $\mathrm{Ca}^{2+}, \mathrm{Mg}^{2+}$-free saline supplemented with EDTA. The cells were plated on clean glass coverslips and were used for experiments after $24 \mathrm{hr}$ at room temperature $\left(20-22^{\circ} \mathrm{C}\right.$ ). The culture medium consisted of 50\% (vol/vol) of Ringer's solution ( $115 \mathrm{~mm} \mathrm{NaCl}, 2 \mathrm{~mm} \mathrm{CaCl}, 2.5 \mathrm{~mm} \mathrm{KCl}, 10 \mathrm{~mm}$ HEPES, pH 7.6), 49\% L-15 Leibovitz's medium (Sigma) and 1\% fetal bovine serum (GIBCO). Isolated neurons and myocytes in $1 \mathrm{~d}$ old Xenopus nervemuscle cultures were used for the present study.

For studying ACh secretion from fibroblasts, an amphibian cell line FT (American Tissue Culture Collection, Rockville, MD) was used as a source of fibroblasts. The cells were grown in MEM (Sigma) supplemented with $10 \%$ fetal bovine serum (GIBCO), nonessential amino acids, and penicillin-streptomycin ( $\mathrm{pH} 7.6$ ). The fibroblasts were used 1$5 \mathrm{~d}$ after subculturing in this medium at $25^{\circ} \mathrm{C}$ in a $5 \% \mathrm{CO}_{2}$ environment

Eserine (physostigmine) was obtained from Sigma (Sainl Louis, MO). Bis-(o-aminophenoxy)-ethane- $N, N, N^{\prime}, N^{\prime}$-tetraacetic acid (BAPTA) was obtained from Sigma. The tetra(acetoxymethyl)-ester form of BAPTA (BAPTA-AM) and ionomycin were obtained from Calbiochem (San Diego, CA). Phorbol 12,13-dibutyrate (PDBu) was obtained from RBI (Natick, MA).

Cytoplasmic loading of ACh. Fibroblasts were loaded by intracellular injection of $\mathrm{ACh}$ with a conventional glass microelectrode which had been beveled to tip opening of about $0.5 \mu \mathrm{m}$. The electrodes were filled with $400 \mathrm{~mm}$ ACh dissolved in water. A $10-20 \mathrm{msec}$ pulse of positive pressure was applied by a picospritzer (General Valve $\mathrm{Co}$.). The amount of solution injected into the fibroblasts was estimated to be less than $5 \%$ of the cell volume (Graessmann et al., 1980), thus giving a final concentration in the cytoplasm of approximately $25 \mathrm{~mm}$ ACh in a typical experiment. The myocytes were loaded with $\mathrm{ACh}$ through the whole-cell pipette containing internal solution supplemented with 20 mM ACh (Dan and Poo, 1992).

Electrophysiology. Whole-cell patch-clamp recording methods were used as described previously (Hamill et al., 1981; Young and Poo, 1983; Fvers et al., 1989). Recordings of spontaneous quantal $\mathrm{ACh}$ secretion were made at room temperature in culture medium from the myocyte, which was voltage-clamped at a holding voltage of $-70 \mathrm{mV}$. The solution inside the recording pipette contained $150 \mathrm{mM} \mathrm{KCl}, 1 \mathrm{mM} \mathrm{NaCl}$, $1 \mathrm{mM} \mathrm{MgCl}$, and $10 \mathrm{~mm}$ HEPES buffer ( $\mathrm{pH} \mathrm{7.2).} \mathrm{The} \mathrm{membrane} \mathrm{cur-}$ rents were monitored by a patch-clamp amplifier (Axopatch-1A). To assess $\mathrm{ACh}$ secretion from isolated neurons, a micropipette was used to carefully detach a spherical myocyte from the coverglass and to manipulate the myocyte into contact with the growth cone of a cocultured spinal neuron (Evers et al., 1989). Similarly, isolated myocytes were manipulated into contact with fibroblasts to detect $\mathrm{ACh}$ secretion from these cells. In the study of myocyte secretion, we recorded the currents generated by quantal $\mathrm{ACh}$ secretion in the same myocyte that was loaded with ACh (autoreception). In several experiments, a second myocyte was manipulated into contact with the $\mathrm{ACh}$-loaded myocyte and the membrane currents in both cells were recorded simultaneously by two whole-cell recording pipettes. Iontophoresis of $\mathrm{ACh}$ was applied to the surface of the myocyte by conventional glass microelectrode as described by Poo (1982).

Electrophysiological data were stored on a videotape recorder for later playback onto a storage oscilloscope (Tektronix 5113) or an oscillographic recorder (Gould RS3200). The data were digitized and analyzed with the SCAN program kindly provided by Dr. J. Dempster, University of Strathclyde, U.K. In some experiments, the Enhanced Graphics Acquisition and Analysis software (EGAA) of R.C. Electronic (Goleta, CA) was also used. The following parameters of the currents were computed: (1) the peak amplitude; (2) the rise time between the $10 \%$ to the $90 \%$ percent of the peak amplitude on the rising phase; (3) the half-decay time, that is the time elapsed between the peak of the response down to half its amplitude on the decaying phase; (4) the time integral of charge carried by the spontaneous MEPCs, measured as the area under the signal from the $10 \%$ peak level in the rising phase to the end of the analysis area (usually $50-100 \mathrm{msec}$ ).

Fluorescence imaging of $\left[\mathrm{Ca}^{2+}\right]_{\mathrm{i}}$. Intracellular $\mathrm{Ca}^{2+}$ concentration was measured by using Fura-2 fluorescence ratio imaging method. Briefly, the cells were loaded with Fura-2 by incubation with $6 \mu \mathrm{M}$ Fura-2AM (Molecular Probe, Eugene, OR) for $30 \mathrm{~min}$ at room temperature $\left(20-22^{\circ} \mathrm{C}\right)$. After thorough washing, the cells were imaged with an inverted microscope (DIAPHOT, Nikon) equipped with a cooled CCD camera-based imaging system (CH200 CCD camera, Photometrics LTD, Tucson, AZ). A Nikon $40 \times / 1.3$ NA Fluor DL objective lens was used throughout the experiments. Fura-2 was excited at 340 and 380 $\mathrm{nm}$ wavelengths alternately through a computer-controlled shutter and filter wheel. The exposure time at each wavelength was $100 \mathrm{msec}$. Paired digital images at 340 and $380 \mathrm{~nm}$ excitation were collected with background subtracted. The cytosolic-free $\mathrm{Ca}^{21}$ concentration was determined from the ratio $\left(F_{340} / F_{380}\right)$ calculated from the pairs using the ratio method (Grynkiewicz et al., 1985; Tsien and Poenie, 1986). Calibration of $R_{\min }$ (the limiting value that the ratio can have at zero $\left[\mathrm{Ca}^{2+}\right]$ ) and $R_{\max }$ (the limiting value that the ratio can have at saturating $\left[\mathrm{Ca}^{2+}\right.$ ) was carried out using standard $\mathrm{Ca}^{2+}$ buffers with zero and $39.8 \mu \mathrm{M}$ free $\left[\mathrm{Ca}^{2+}\right]$ (Molecular Probes, Inc.).

\section{Results}

Quantal ACh secretion from neurons, myocytes, and

\section{fibroblasts}

Isolated embryonic spinal neurons in Xenopus cultures established functional synaptic transmission with cocultured myocytes soon after nerve-muscle contact (Chow and Poo, 1985; Xie and Poo, 1986). Spontaneous pulsatile membrane currents resembling minialure endplate currents (MEPCs) were detected in a whole-cell voltage-clamped myocyte immediately after it was manipulated into contact with the growth cone of an isolated spinal neuron (see Fig. $1 A$ ). The frequency and amplitude of the current events increased gradually, reaching a plateau within the first $10 \mathrm{~min}$ following the contact. For events observed during the first 10-20 min of contact, the mean frequency of MEPCs was $24 \pm 5.5$ events/min (SEM, $n=10$; see Table 1 ).

Pulsatile ACh secretion from fibroblasts was examined one day after plating of the cells. The fibroblast was pressure-injected with ACh using a conventional glass micropipette. The concentration of $\mathrm{ACh}$ in the cytoplasm following injection of the fibroblasts was estimated to be about $25 \mathrm{~mm}$ (see Material and Methods). Within minutes following intracellular injection, a cultured Xenopus myocyte was manipulated into contact with the fibroblast. Whole-cell recording from the myocyte revealed transient inward currents resembling MEPCs (Fig. 1B). These currents reflect pulsatile release of $\mathrm{ACh}$ from the injected fibrohlasts, since they were totally abolished by bath-application of $d$-tubocurarine ( $1 \mathrm{mM}, n=5$ ), and no such current was observed from fibroblasts that were not injected with $\mathrm{ACh}(n=5)$. In this report, we refer to these MEPC-like events observed at the surface of fibroblasts as "f-MEPCs." These events were observed immediately after the onset of myocyle recording, usually 5 min following $\mathrm{ACh}$ injection, and their frequency and amplitude increased gradually with time, reaching a plateau level within 30 min. These secretion events appear to result from the accumulation and subsequent exocytosis of $\mathrm{ACh}$ by vesicles in the constitutive secretion or membrane recycling pathways. They are very similar in amplitude and time course to those seen after loading the endocytotic compartments of these fibroblasts with $\mathrm{ACh}$, via a brief incubation of the fibroblasts in a solution containing ACh (Alder et al., 1993). At 30 min after ACh injection, the frequency of $\mathrm{f}-\mathrm{MEPCs}$ was $15.0 \pm 2.1$ events/min (SEM, $n$ $=8$ ). This value was lower than the MEPC frequency at newly formed synapses between the myocyte and the growth cone of spinal neuron (see Table 1).

Isolated myocytes in the same Xenopus cultures also exhibited spontaneous quantal $\mathrm{ACh}$ release when they were loaded with 10-30 $\mathrm{mm}$ ACh through a whole-cell recording pipcttc, as shown by pulsatile activation of their own surface ACh receptors (autoreception) and induction of MEPC-like events in the myocytes (Fig. 1C; see Dan and Poo, 1992). These currents will be referred to as "m-MEPCs." They appeared after several minutes of delay following the onset of loading, and their amplitude and frequency increased with time, reaching a plateau in about 10 

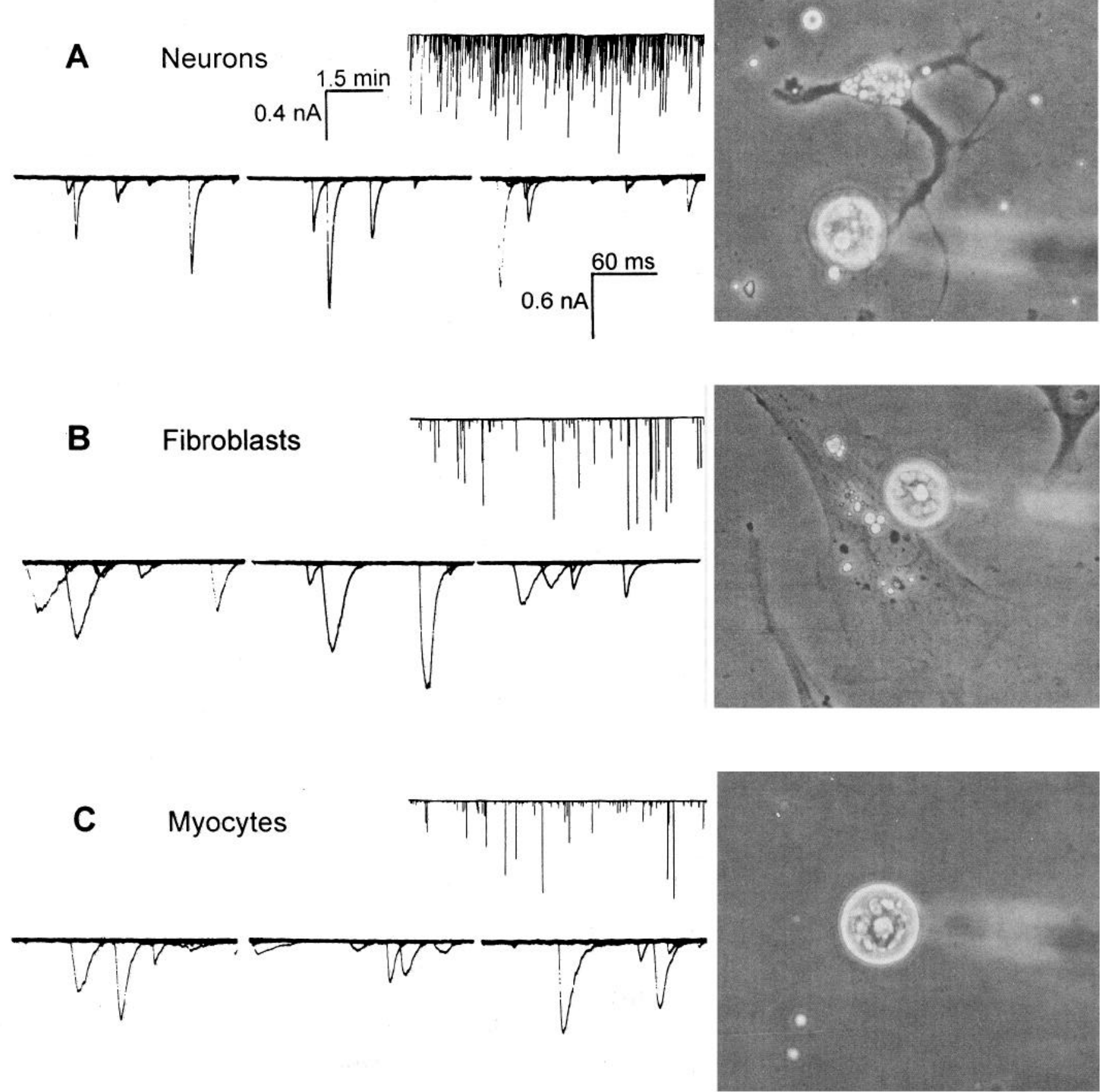

Figure 1. Spontaneous quantal release of ACh from a developing Xenopus spinal neuron $(A)$, an amphibian fibroblast (B), and from a Xenopus myocyte $(C)$. ACh was loaded into the cytoplasm of the non-neuronal cells, via pressure injection in the case of the fibroblast and through the whole-cell recording patch pipette in the case of the myocyte. On the right, the phase-contrast photographs depict the experimental procedure used to detect ACh secretion. A whole-cell clamped Xenopus myocyte (diameter is about $30 \mu \mathrm{m}$ in $A$ ) used as an ACh probe was manipulated into contact with the neuron $(A)$ and the ACh-loaded fibroblast $(B)$. Secretion from the ACh-loaded myocyte $(C)$ was detected by autoreception through its own surface $\mathrm{ACh}$ receptors. On the left, the continuous traces illustrate membrane current (filtered at $150 \mathrm{~Hz}$ ) during a period of $8 \mathrm{~min}$ of recording through the myocyte under whole-cell voltage-clamp conditions (holding potential $=-70 \mathrm{mV}$ ). Inward currents, shown as downward deflections, result from quantal ACh secretion from the three cell types. Samples of current events are shown below at a higher time resolution. In $A$ the traces illustrates the synaptic activity as recorded from $7 \mathrm{~min}$ to $15 \mathrm{~min}$ after contact of the myocyte with the neuron. In $B$ and $C$, the traces starts 30 min after the onset of ACh loading.

$20 \mathrm{~min}$. The gradual appearance of these events presumably reflects the time required for $\mathrm{ACh}$ diffusion into the cytoplasm and for the loading of vesicular compartments within the myocyte, as suggested by the results of pharmacological experiments
(Dan and Poo, 1992). For all recordings made in the present study, the mean frequency of m-MEPCs within $30 \mathrm{~min}$ to 1.5 $\mathrm{hr}$ after ACh loading as measured by autoreception was $5.3 \pm$ 0.8 events/min (SEM, $n=8$ ). 
Table 1. Electrophysiological parameters of $\Lambda \mathrm{Ch}$ secretion from developing neurons, fibroblasts, and myocytes

\begin{tabular}{lllllll} 
Median & Amplitude $(\mathrm{nA})$ & $\begin{array}{l}\text { Integrated } \\
\text { charge }(\mathrm{pC})\end{array}$ & Rise time (msec) & $\begin{array}{l}\text { Half-decay } \\
\text { time }(\mathrm{msec})\end{array}$ & $\begin{array}{l}\text { Frequency } \\
(\text { event/min) }\end{array}$ & Breaks $(\%)$ \\
\hline Neurons (10) & $0.116 \pm 0.014$ & $0.73 \pm 0.14$ & $1.3 \pm 0.1$ & $3.7 \pm 0.3$ & $24.0 \pm 5.5$ & $5.4 \pm 0.5$ \\
Fibroblasts (8) & $0.098 \pm 0.018$ & $1.22 \pm 0.30$ & $3.8 \pm 0.7^{* *}$ & $6.2 \pm 0.9^{*}$ & $15.0 \pm 2.1^{*}$ & $9.8 \pm 1.3^{*}$ \\
Myocytes (8) & $0.061 \pm 0.008^{* \dagger}$ & $1.01 \pm 0.12$ & $3.7 \pm 0.2^{* *}$ & $7.1 \pm 0.8^{* *}$ & $0.6 \pm 0.2^{* *} \neq$ & $9.5 \pm 1.0^{* *}$
\end{tabular}

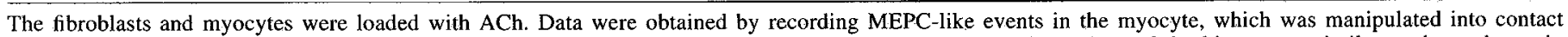

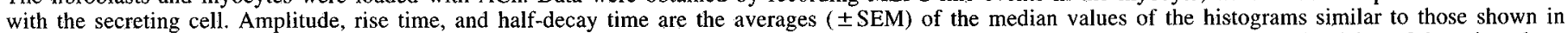

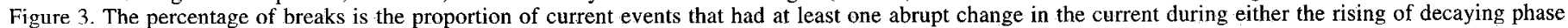

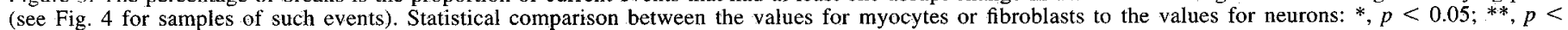

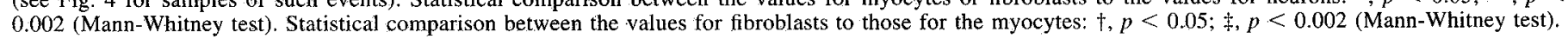

In contrast to fibroblast and neuronal secretion, the current events detected with autoreception in the isolated myocytes reflected ACh secretion over the entire surface of the cell. To determine whether autoreception altered the characteristics of m-MEPCs, a second whole-cell clamped myocyte was used for detection of $\mathrm{ACh}$ secretion by manipulating it into contact with the ACh-loaded myocyte (see Fig. 2). The diameter of the loaded myocyte (assumed spherical) and that of the surface area of contact (assumed circular) were measured, and the ratio of the surface of contact to that of the whole loaded myocyte was $9.9 \%$ $\pm 1.4 \%(n=13)$. When the currents in both myocytes were monitored simultaneously with two separate patch-clamp amplifiers, we found that $12.0 \pm 2.9 \%$ (SEM, $n=13$ ) of the events in the secreting ("presynaptic") myocyte were accompanied by a coincident event in the detecting ("postsynaptic") myocyte (Fig. 2B). 'These coincident events are apparently due to $\mathrm{ACh}$ secreted within the site of contact between the two myocytes, resulting in simultancous activation of both cells. Thus the probability of detecting m-MEPCs with a manipulated cell was similar to the fraction of surface area on the "presynaptic" myocyte contacted by the "postsynaptic" myocyte. This suggests that $\mathrm{ACh}$ secretion was uniformly distributed on the surface of the ACh-loaded myocyte. The mean m-MEPC frequency in the detecting myocyte was $0.6 \pm 0.2$ events $/ \mathrm{min}(\mathrm{SEM}, n=11)$. This value was much lower than that at newly formed synapses and at fibroblasts (Table 1). In two experiments, one of which is illustrated in Figure 2, the particularly high secretion frequency produced a sufficiently large number of "postsynaptic" events, and histogram analyses of their time course and amplitude could be performed. "Postsynaptic" $m$-MEPCs were found to have amplitude and rise time distributions similar to those of "presynaptic" m-MEPCs, and the half decay time distribution of the two groups of m-MEPCs also showed substantial overlap. However, the incidence of $\mathrm{m}$-MEPCs with half decay times longer than $30 \mathrm{msec}$ was higher in the pre- than in the postsynaptic myocyte (1.1\% and $14.7 \%$, respectively; Fig. $2 C$ ). Similar results were found in the second experiment. These data indicate that, although a larger variability in their decay rates may be expected, m-MEPCs recorded with the autoreception method were in most aspects similar to m-MEPCs recorded with a second manipulated myocyte. Since autoreception yiclded a much larger number of m-MEPCs, this method was used throughout the rest of the present work when $\mathrm{ACh}$ secretion from myocytes was analyzed.

\section{Analysis of the amplitude and time course of MEPCs}

The amplitude distribution of MEPCs was examined for all three cell types. The overall profile of the amplitude distributions was similar; all exhibited a skewed distribution towards smaller am- plitudes (Fig. 3). As shown in Table 1, the median size of f-MEPCs $(0.098 \mathrm{nA})$ did not significantly differ from that of MEPCs $(0.116 \mathrm{nA})$. By contrast, the median amplitude of m-MEPCs $(0.061 \mathrm{nA})$ was significantly smaller than those of both f-MEPCs and MEPCs. Large current events with amplitudes in the range of $0.8-1.0 \mathrm{nA}$ or more, although less frequent in myocytes, were seen in all three cell types. When the current was integrated with time to obtain total charge movement through the detecting myocyte membrane triggered by quantal ACh packets, the values for the three cell types were not statistically different from one another $(p>0.1$, Mann-Whitney test; see Table 1). Thus, the apparent difference in the peak amplitude of MEPCs is likely to result from the time course of ACh secretion and/or reception rather than from the total amount of ACh contained in the quantal packets.

The fluctuation of total charge movements generated by the quantal packets was estimated by calculating the coefficient of variation (CV), as defined by the ratio of the standard deviation of the total charge movement to its mean value. The $\mathrm{CV}$ for neuronal MEPCs was $109.7 \pm 6.5 \%$ (SEM, $n=10$ ) which is significantly lower ( $p<0.05$, Mann-Whitney test) than that for fibroblasts and myocytes $(145.5 \pm 11.1 \%$, SEM, $n=8$ and $158.1 \pm 15.2 \%, \mathrm{SEM}, n=8$, respectively). Thus, despite the similarity in the average amount of $\mathrm{ACh}$ in the quantal packets secreted by the three cell types, there is higher variability in the individual ACh packets in myocytes and fibroblasts.

Although ACh secretion from the non-neuronal cells was pulsatile in nature, non-neuronal MEPCs had slower time course and more irregular shapes than those at newly formed nervemyocyte contacts. These features can clearly be seen when individual MEPCs are considered (see Fig. 1). As quantified in Table 1 and in Figure 3, f- and m-MEPCs had similar median rise times and half decay times. The mean rise time and halfdecay time of neuronal MEPCs were significantly shorter. Furthermore, the distributions of the rise times and half-decay times for f-MEPCs and m-MEPCS were much more scattered than those of neuronal MEPCs (Fig. 3). Rise times of up to $50 \mathrm{msec}$ were seen in the non-neuronal cells, whereas the rise times of neuronal MEPCs rarely exceeded 5-6 msec. The decaying phase of m-MEPCs was particularly variable; about $8 \%$ of all the events had a half decay time of more than $30 \mathrm{msec}$, and values up to $150 \mathrm{msec}$ were observed. Such high variability was expected from the autoreception method used to detect $\mathrm{ACh}$ release in myocytes (see above). At fibroblasts, only $0.5 \%$ of the events had a half-decay time longer than $30 \mathrm{msec}$ and al neuromuscular synapses the half decay time rarely exceeded 10 msec.

Some of the slow events seen in fibroblasts and myocytes had 

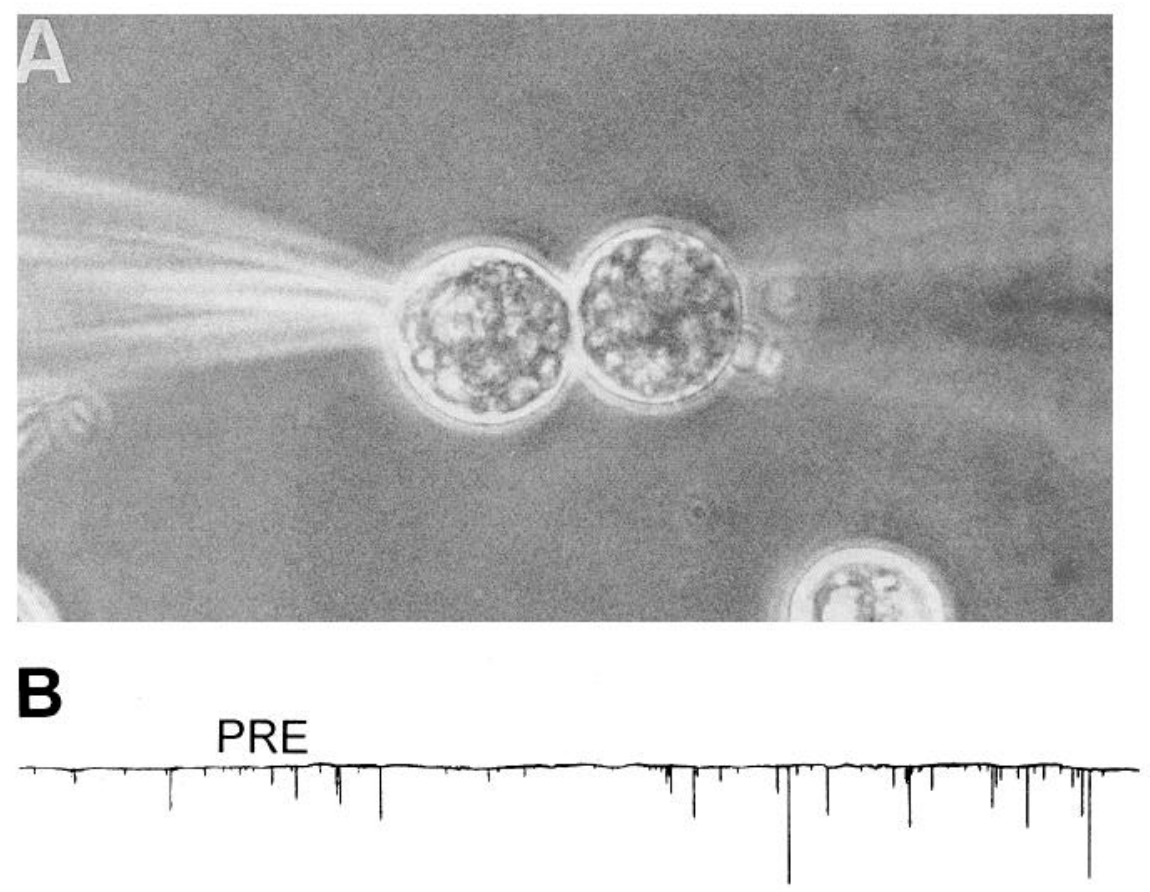

Figure 2. Detection of quantal $\mathrm{ACh}$ release from an ACh-loaded ("presynaptic") myocyte by a second ("postsynaptic") myocyte. The experimental protocol is illustrated in A (diameter of the myocytes are about $30 \mu \mathrm{m})$. The two myocytes were brought into contact and the currents in both cells were recorded under voltage-clamp conditions with two separate whole-cell recording pipettes (holding potential = $-70 \mathrm{mV}$ in both cells). Only one of the two myocytes (cell on the right) was loaded with ACh $20 \mathrm{~mm}$ through the patch pipette. Continuous traces in $B$ depict at two different time scales the currents recorded in the pre- and the postsynaptic cells simultaneously. Some of the presynaptic m-MEPCs (traces labeled $P R E$ ) were accompanied by coincident events in the postsynaptic myocyte (traces labeled POST). Coincident m-MEPCs (marked by the arrows in the bottom traces shown with a high time resolution) correspond to quantal $\mathrm{ACh}$ release at the site of contact between the two myocytes. Note a corresponding break observed on a pair of coincident m-MEPCs (marked by the asterisk). $C$, Amplitude and time course histograms of the postsynaptic $\mathrm{m}$-MEPCs were compared to those of the presynaptic MEPCs. No differences were found, except a higher incidence in the presynaptic cell of currents with a half-decay time longer than $30 \mathrm{msec}$.
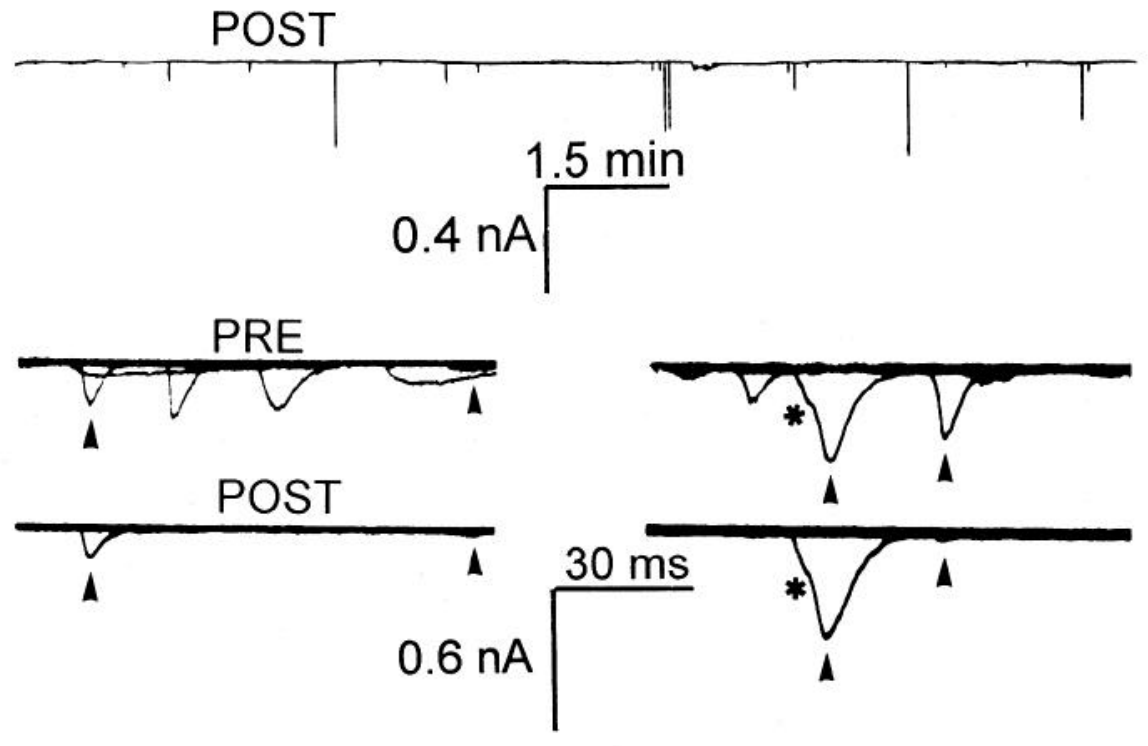

C
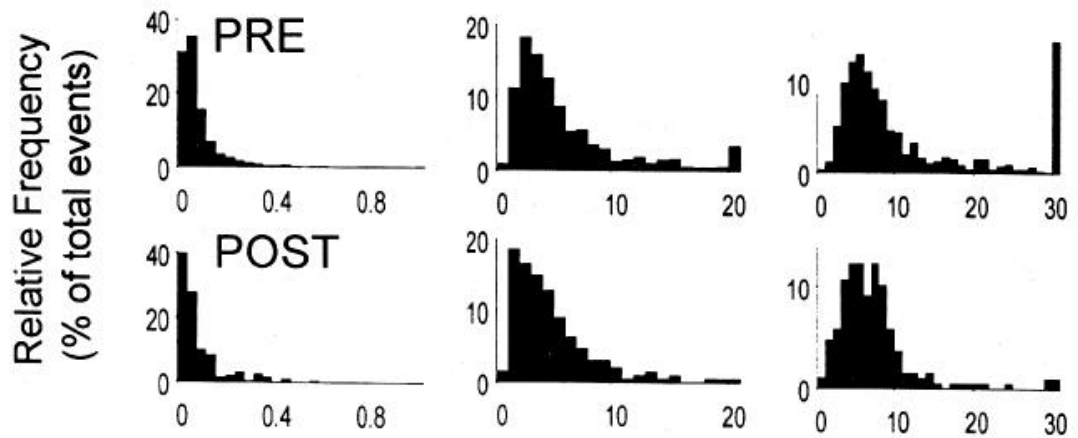

Amplitude (nA) 
A

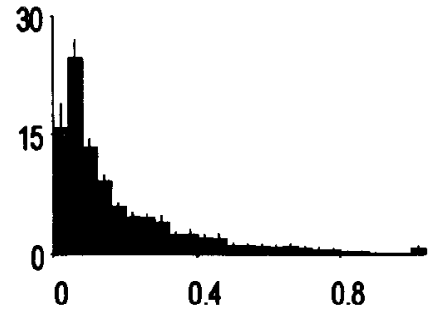

B
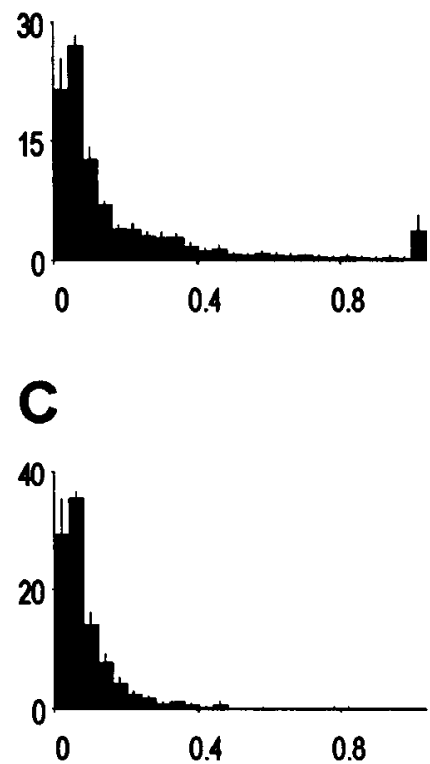

\section{Amplitude (nA)}

\section{Neurons}
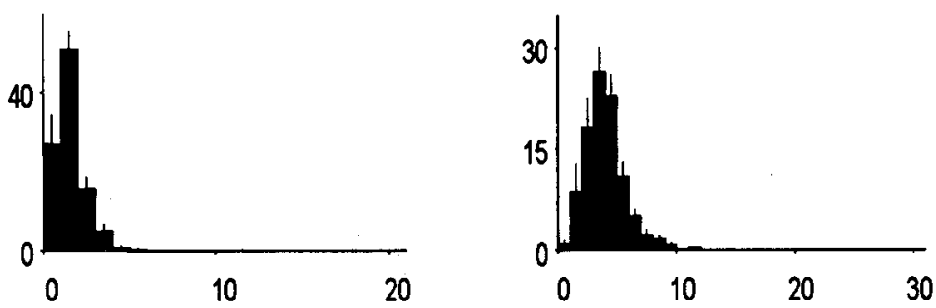

Fibroblasts

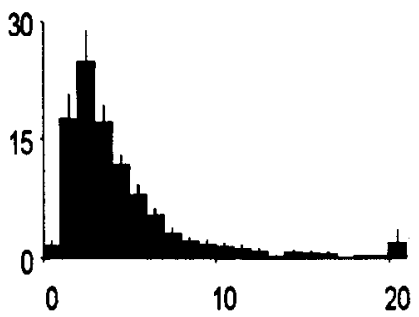

Myocytes
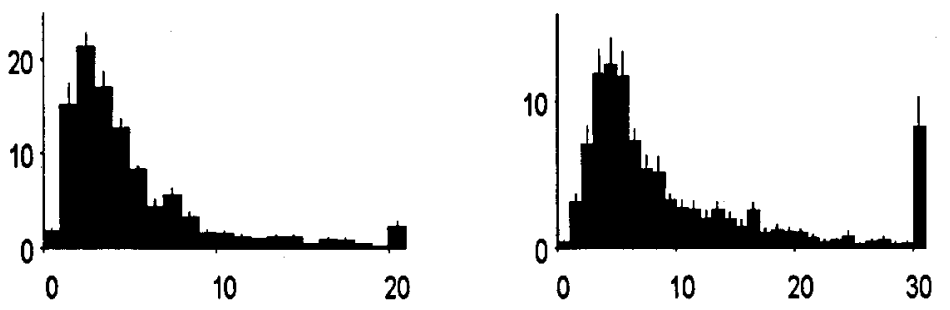

Figure 3. Distribution of the amplitude, rise time and half-decay time of the MEPC-like events generated by developing neurons $(A)$, ACh-loaded fibroblasts $(B)$, and ACh-loaded myocytes $(C)$. Data were groupcd in $0.04 \mathrm{nA}$ bins for the amplitude, and in $2 \mathrm{msec}$ bins for the rise time and halfdecay time. Each histogram bar is the mean relative frequency \pm SEM of 10 neurons, 8 fibroblasts, and 8 myocytes. Comparable skewed amplitude distributions were found in all three cell types, although the median amplitude was slightly smaller in myocytes than in neurons and in fibroblasts. The rise time and half-decay time distributions for fibroblasts and myocytes had larger median values and were more scattered than those for neurons.

a highly irregular (atypical) time course, with sometimes abrupt changes in their rate of rise and/or decay (see Fig. $4 B, C$ ). Inspection of all data revealed that some $10 \%$ of all events seen in fibroblasts and myocytes had atypical shapes (Table 1). Atypical MEPCs were also found at newly formed synapses (see Fig. $4 A$ ), but their time course was less irregular and their incidence was only $5 \%$ (Table 1 ). In the double patch recording of myocyte secretion described above, we noted that when a break occurred in the rise and/or the decay phase of a presynaptic m-MEPC, the same break was also found on the coincident $m-M E P C$ in the postsynaptic myocyte (see asterisk in Fig. $2 B$ ). This findings suggest that the atypical time course probably reflects irregular secretion rather than irregular detection of the quantal $\mathrm{ACh}$ packets. If discontinuous postsynaptic surface $\mathrm{ACh}$ sensitivity was the origin of the abnormal shapes, then one would assume the improbable hypothesis that identical irregularity occurred simultaneously on both pre- and postsynaptic myocyte surfaces.
It appears more likely that discontinuous $\mathrm{ACh}$ secretion gave rise to the irregular shape of m-MEPCs. Moreover, we noted that the break on the postsynaptic m-MEPC was usually less pronounced than the break on the presynaptic event (see asterisk in Fig. $2 B$ ). This is expected if diffusion across the gap separating the two myocyte membranes buffers abrupt changes of ACh flux occurring at the release site. Further evidence that atypical currents reflected irregular rate of $\mathrm{ACh}$ secretion are presented below.

\section{Iontophoretic simulation of $M E P C s$ generation}

The rapid and homogenous time course of neuronal MEPCs might depend on a specific architecture and composition of the synaptic cleft which is absent in the case of secretion from fibroblasts and myocytes. Alternatively, the speed of ACh release from neurons might be faster and more regular than the speed of $\mathrm{ACh}$ release from fibroblasts and myocytes. The following 


\section{A Neurons}
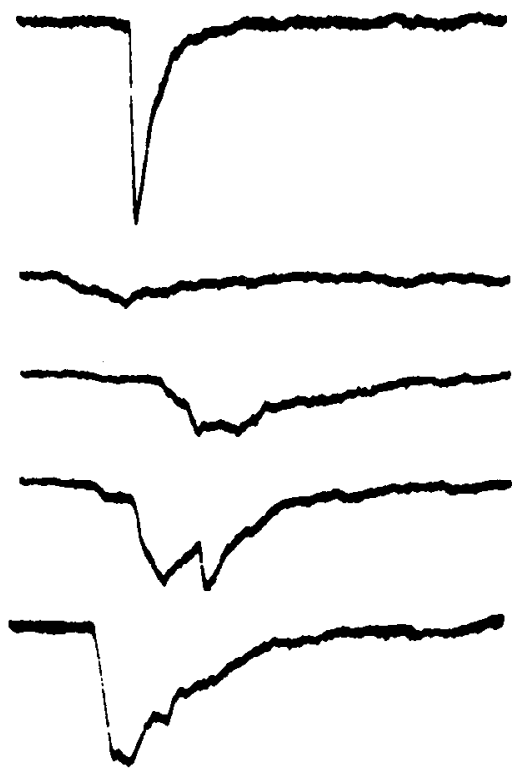

\section{B Fibroblasts}
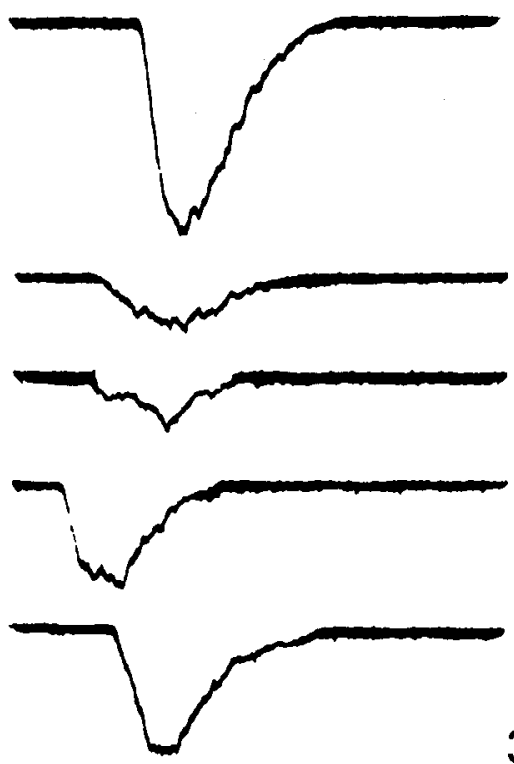

$0.3 \mathrm{nA}$
C Myocytes
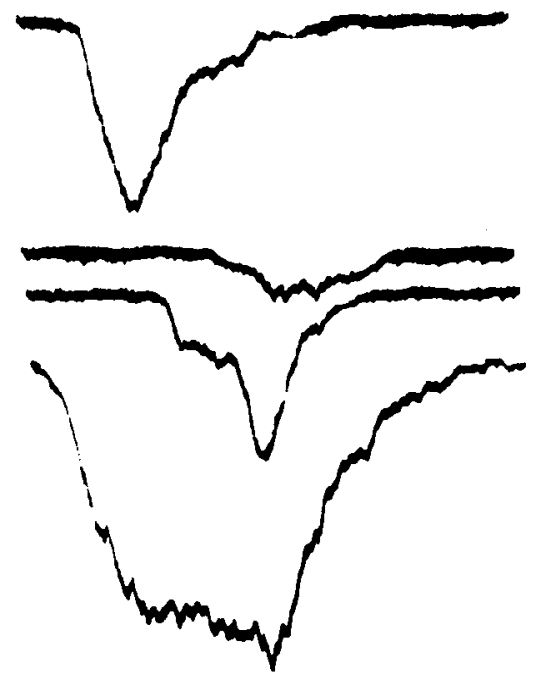

Figure 4. Samples of MEPCs with atypical slow time course for secretion from developing neurons $(A)$, ACh-loaded fibroblasts $(B)$, and AChloaded myocytes $(C)$. For comparison, the first trace in each case illustrates a current event representative of the main population of fast MEPCs observed for each cell type.

experiments were carried out in an attempt to discriminate between these two possibilities.

Iontophoretic pulses of $\mathrm{ACh}$ were applied to the surface of an isolated myocyte to simulate rapid neuronal MEPCs. The tip of the iontophoresis pipette was brought into direct contact with the isolated myocyte to simulate close apposition found between the nerve and muscle membranes at newly formed synapses (Buchanan et al., 1989). Maximal rate of rise in the ACh-induced currents was achieved by giving $\mathrm{ACh}$ pulses with duration of $0.5 \mathrm{msec}$. Shorter ACh pulses did not accelerate the rate of rise. This is consistent with the view that the rate of rise of synaptic currents is determined mainly by the kinetics of ACh diffusion and of receptor activation rather than by the kinetics of $\mathrm{ACh}$ release (see Land et al., 1981). Under these conditions of ACh iontophoresis, $\mathrm{ACh}$ pulses of different amplitudes were applied to a total of 18 sites on seven myocytes and the resulting AChinduced currents were recorded and analyzed. From each of the 18 sites tested, 10 currents were arbitrarily selected so that the amplitude distribution of the ACh-induced currents matched that seen for newly formed synapses, with a median amplitude of about $0.110 \mathrm{nA}$ (see Fig. 5). The resulting currents showed a median rise time of $2.3 \mathrm{msec}$, which is a twofold longer value than that of MEPCs. Thus, the fastest currents obtained with iontophoresis are still slower than synaptic currents; this suggests that the synaptic structure, which at this early stage of synaptogenesis consists of a close and uniform membrane apposition at nerve-muscle contact sites (see Buchanan et al., 1989), increases the rate of rise of MEPCs. Moreover, nerve processes have been shown to specifically induce the formation of $\mathrm{ACh}$ receptor clusters at the site of nerve-muscle contact within several hours of nerve-muscle contact (Anderson et al., 1977; Frank and Fischbach, 1979). Although we have analyzed MEPCs at newly formed synapses within the first 10-20 min of contact, it is possible that microclusters had formed rapidly during this early period of synaptogenesis. Such $\mathrm{ACh}$ receptor clustering may also contribute to the fast rate of rise of neuronal MEPCs.

Comparison between the iontophoretic ACh-induced currents and $\mathrm{m}-\mathrm{MEPCs}$ is also revealing. Brief iontophoretical $\mathrm{ACh}$ pulses should faithfully mimic ACh secretion from isolated myocytes, since in both cases ACh spreads on and activates an open, noninnervated receptive surface. Nevertheless, MEPCs in myocytcs had a risc time $(3.8 \mathrm{mscc})$ substantially slower than the rise time of iontophoretical $\mathrm{ACh}$ currents $(2.3 \mathrm{msec})$. This suggests that the time needed for an ACh pulse to be secreted from a myocyte is longer than the duration of the iontophoretic $\mathrm{ACh}$ pulses used here, and that, in contrast to neuronal secretion, the kinetics of $\mathrm{ACh}$ release in myocytes contributes to the rising rate of $\mathrm{m}$-MEPCs. The simplest explanation for the similar rise lime of f-MEPCs and In-MEPCs is that the speed of ACh release is similar in the two non-neuronal cells. We also noted that the rise time distribution of iontophoretic $\mathrm{ACh}$-induced currents was much less scattered than that of f-MEPCs and m-MEPCs (compare histograms in Figs. 3, 5). With iontophoresis, rise times longer than $8 \mathrm{msec}$ and atypical rising phases comparable to those of Figure 4 were never seen. This further supports the notion that atypical MEPCs were the result of irregular $\mathrm{ACh}$ secretion rather than $\mathrm{ACh}$ reception by the myocyte. 

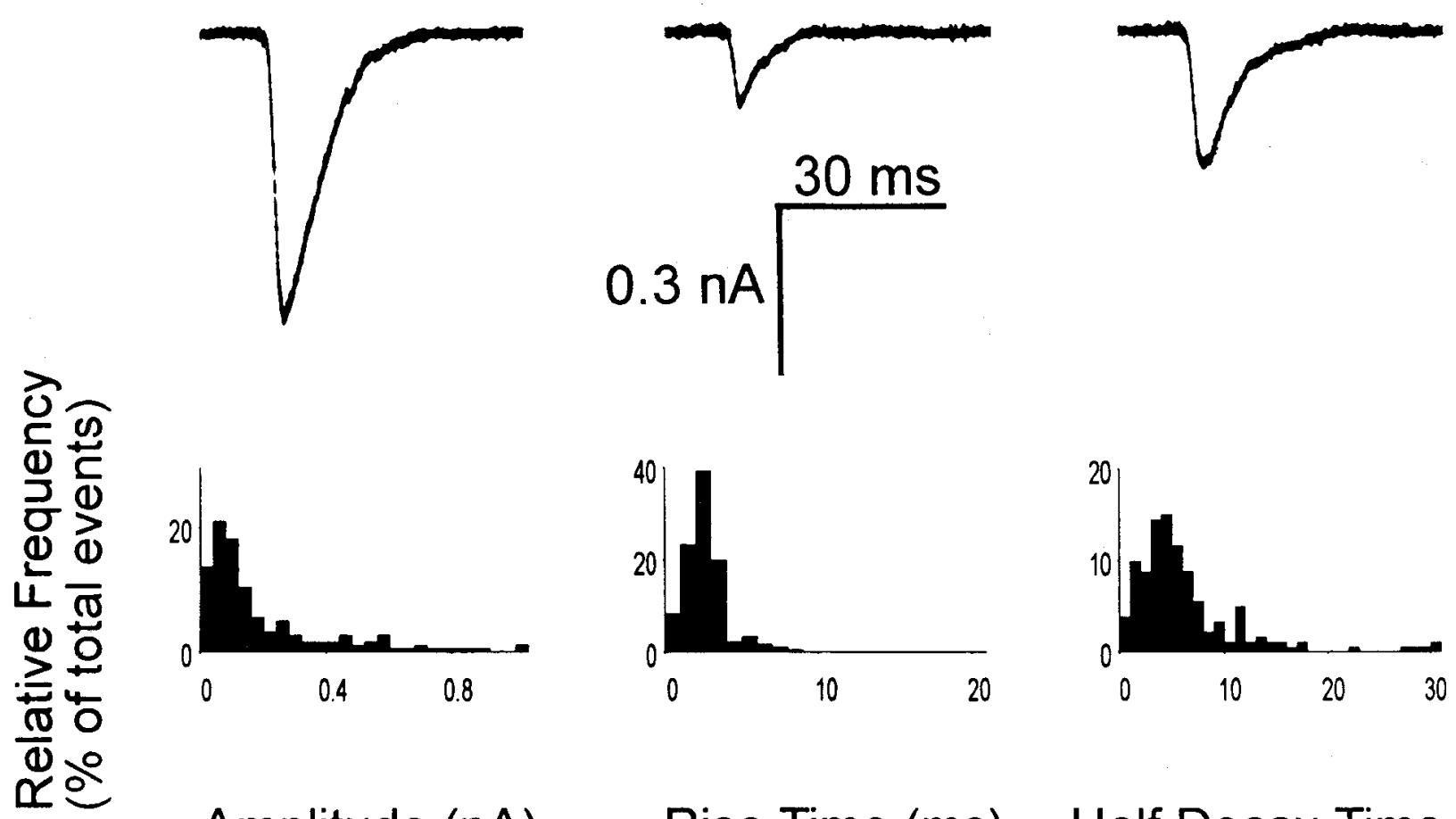

\section{Amplitude (nA)}

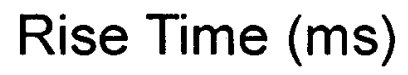

Half Decay Time (ms)

Figure 5. Iontophoretic simulation of MEPCs. Pulses of $\mathrm{ACh}$ (duration $0.5 \mathrm{msec}$ ) were iontophoretically applied to the surface of an isolated myocyte, and membrane currents induced in the myocyte were recorded by whole-cell voltage-clamp recording of the cell $\left(V_{h}=-70 \mathrm{mV}\right)$. The top traces show samples of the ACh currents recorded in the myocyte. The distributions of amplitude, rise times and half-decay times of the AChinduced currents are shown below. The strength of the iontophoretic pulse was varied as to generate a population of currents that had amplitude distribution similar to that of MEPCs recorded at newly formed synapses (see Fig. 3).

The half-decay times of iontophoretic ACh-induced currents had a larger median (4.6 $\mathrm{msec})$ and broader distribution when compared to MEPCs. The half-decay time distribution of $\mathrm{ACh}$ currents was very similar to that of f-MEPCs and m-MEPCs (see Figs. 3, 5). One obvious possibility that could account for the fast decay of neuronal MEPCs is the presence of acetylcholinesterases (AChEs) at the neuron surface. This was tested by exanining the effect of AChE inhibitor eserine on the MEPCs at neuromuscular synapses in these $1 \mathrm{~d}$ old Xenopus cultures. We found that after $1 \mathrm{hr}$ incubation in a medium containing eserine $(0.2-1 \mathrm{mM})$, the median amplitude and the median halfdecay time of MEPCs were $106.3 \pm 21.5 \%$ and $94.5 \pm 15.0 \%$ (SEM, $n=4$ ) of the pretreatment control values, respectively, suggesting that the contribution of ACh hydrolysis by AChEs to the time course of MEPCs is negligible. The differences in the kinetics of $\mathrm{ACh}$ dissociation from the $\mathrm{ACh}$ receptor or the rate of ACh channel closing are also unlikely to account for the slower decay of non-neuronal MEPCs and iontophoretic $\mathrm{ACh}_{-}$ induced currents, since the same myocytes were used to detect $\mathrm{ACh}$ in all cases. Thus, the most likely explanation for the fast decay of MEPCs appears to reside in a faster diffusional dissipation of $\mathrm{ACh}$ at the release site, which may result from a flattening of the myocyte membrane at the site of nerve contact, as shown by the ultrastructural observation of these cultures during the early phase of synaptogenesis (Buchanan et al., 1989).

In conclusion, both higher speed of $\mathrm{ACh}$ release and the specific structure of the nerve-myocyte contact appear to contribute to the fast time course of synaptic currents when compared to currents produced by non-neuronal cells.

\section{Ca $a^{2+}$ sensitivity}

Spontaneous secretion from embryonic neurons (Tabti and Poo, 1990) and from ACh-loaded myocytes (Dan and Poo, 1992) have been shown to be increased by treatments which elevate intracellular calcium $\left(\left[\mathrm{Ca}^{2+}\right]_{i}\right)$. Here, we have tested whether high $\left[\mathrm{Ca}^{2+}\right]_{i}$ would potentiate secretion from fibroblasts as well. For that purpose, secretion from ACh-injected fibroblasts was recorded for a control period of $30 \mathrm{~min}$, by which time the f-MEPC frequency had stabilized (see above). The $\mathrm{Ca}^{2+}$ ionophore ionomycin was then applied to the bath at a final concentration of $10 \mu \mathrm{M}$. In these experiments, BAPTA $(10 \mathrm{~mm})$ was included in the intrapipette solution to prevent ionomycin-induced $\mathrm{Ca}^{2+}$ rise in the detecting myocyte, which would have altered the stability of the whole-cell recording. The frequency of $\mathrm{f}-\mathrm{MEPC}$ increased gradually after ionophore treatment (see Fig. 6). At $12 \mathrm{~min}$ after the onset of treatment with ionomycin the frequency of secretion was $2.7 \pm 0.4$-fold $(\mathrm{SEM}, n=7)$ of that before treatment. In comparison, the effect of ionomycin on neuronal secretion at developing Xenopus neuromuscular synapses in culture was also assayed. Within 2-5 min, ionomycin caused massive secretion from neurons, with MEPC frequency $20 \pm 1.2$ times (SEM, $n=3$ ) higher than that observed prior to addition of the ionophore (data not shown). Thus, the sensitivity of fibroblast secretion to elevated $\left[\mathrm{Ca}^{2+}\right]_{i}$ was much smaller than that of neuronal secretion.

We further compared the sensitivity on $\left[\mathrm{Ca}^{2+}\right]_{i}$ of $\mathrm{ACh}$ secretion in the three cell types by reducing intracellular $\mathrm{Ca}^{2+}$ with the membrane-permeable $\mathrm{Ca}^{2+}$ chelator BAPTA-AM. We first used ratio imaging of Fura- 2 to monitor the effect of BAPTA- 


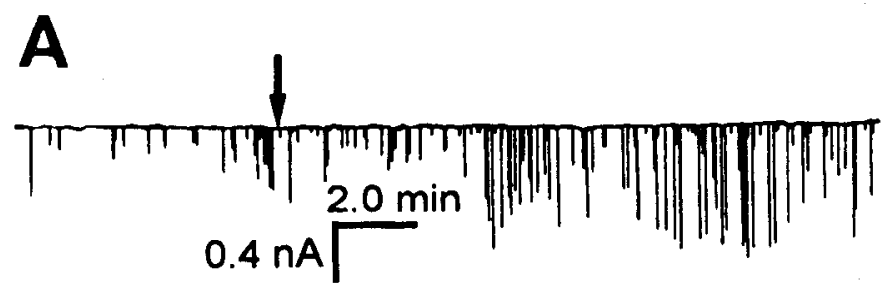

B

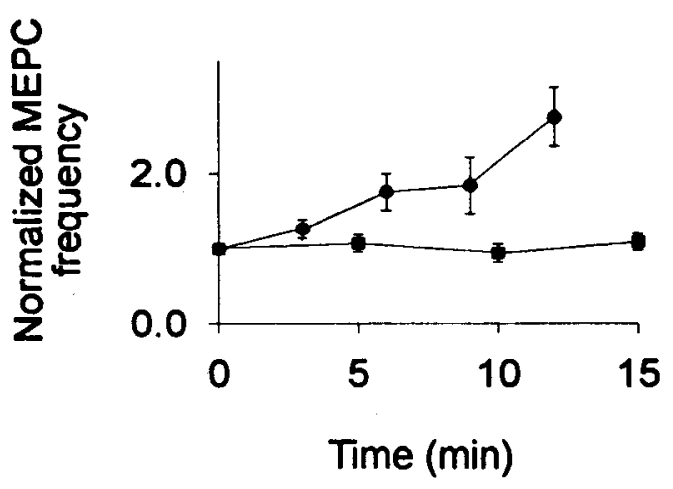

Figure 6. Effect of the $\mathrm{Ca}^{2+}$ ionophore ionomycin on fibroblast secretion. In $A$ the current trace illustrates an example of recording from a myocyte in contact with an ACh-loaded fibroblast, similar to that shown in Figure $1 B$. The trace starts $25 \mathrm{~min}$ after the onset of loading with ACh. Ionomycin (final concentration $10 \mu \mathrm{M}$ ) was added to the external medium at the time marked by the arrow, or time 0 in the graph shown in $B$. In this graph, the data were normalized to the average frequency recorded during the previous $10 \mathrm{~min}$ for each fibroblast. Each data point is the mean normalized MEPC frequency $\pm S E M$ of nine cells for control (squares) and of seven cells for ionomycin-treated fibroblasts (circles). Ionomycin caused a gradual increase of the MEPC frequency, whereas in the absence of the ionophore the frequency of secretion remained stable.

AM on the cytosolic $\mathrm{Ca}^{2+}$ concentrations. At neuronal soma, the $\left[\mathrm{Ca}^{2+}\right]_{i}$ measured prior to BAPTA-AM addition was $393.3 \pm$ $74.4 \mathrm{nM}$ (SEM, $n=6$ ). Thirty minutes after BAPTA-AM addition (final concentration $20 \mu \mathrm{M}$ ), the calcium concentration was $311.5 \pm 94.8 \mathrm{nM}$ (SEM, $n=6$ ), that is a decrease to 72.6 $\pm 7.2 \%$ of the control level of $\mathrm{Ca}^{2+}$. When the $\mathrm{Ca}^{2+}$ concentration before was compared to that after BAPTA-AM addition in each individual cell, the decrease was found statistically significant ( $p<0.05$, paired Student $t$ test). In fibroblasts and myocytes, the resting calcium concentrations were $126.4 \pm 14.6$ $\mathrm{nm}$ (SEM, $n=15$ ) and $144.4 \pm 26.0 \mathrm{~nm}$ (SEM, $n=16$ ), respectively. Both values were lower than that in the neuronal soma, but not different from each other $(p>0.05$, Mann-Whitney test). After BAPTA-AM treatment, the $\left[\mathrm{Ca}^{2+}\right]_{i}$ in fibroblasts and in myocytes showed significantly reduction to, respectively, $84.1 \pm 3.5 \%(p<0.01$, paired Student $t$ test $)$ and $87.3 \pm 7.1 \%$ ( $p<0.05$, paired Student $t$ test) of the values before treatment. Figure 7 shows the time course of $\left[\mathrm{Ca}^{2+}\right]_{i}$ changes after BAPTA treatment. These results indicates that BAPTA-AM decreased the $\left[\mathrm{Ca}^{2+}\right]_{i}$ in all three cell types, but the extend of this decrease was significantly higher ( $p<0.05$, Mann-Whitney test) in neurons than in non-neuronal cells. On the other hand, the decrease of $\left[\mathrm{Ca}^{2+}\right]_{i}$ induced by BAPTA in fibroblasts was similar to that induced in myocytes ( $p>0.05$, Mann-Whitney test).

The effect of BAP'IA-AM treatment on the frequency of spontaneous ACh secretion in the three cell types was examined.
A myocyte was manipulated into contact with an isolated neuron and MEPCs were recorded usually 3-5 min after the neuronmyocyte contact. After a $10 \mathrm{~min}$ period of control recording, at which time the MEPC frequency and mean amplitude had reached a plateau, a solution containing BAPTA-AM (final concentration $20 \mu \mathrm{M}$ ) was bath applied. At $30 \mathrm{~min}$ after the onset of BAPTA-AM treatment, the MEPC frequency was reduced to $22 \%$ of that prior to BAPTA-AM application (Fig. $7 D$, Tablc 2). The mean amplitude of MEPCs, however, was not affected by the treatment (data not shown). This reduction in MEPC frequency was not observed in control cultures, which showed a slight drop to $80 \pm 25 \%$ of the initial frequency. A slight drift of the myocyte away from the neuron during the recording period, resulting in a smaller area of contact, might account for the small reduction of MEPC frequency in control cultures.

To study the sensitivity of myocyte secretion to $\left[\mathrm{Ca}^{2+}\right]_{i}$, isolated myocytes were loaded with ACh for $30 \mathrm{~min}$, then BAPTAAM $(20 \mu \mathrm{M})$ was added to the recording bath and m-MEPCs were recorded for an additional $30 \mathrm{~min}$. In control cells, following the initial increase in MEPC frequency (see above), the rate of $\mathrm{ACh}$ release detected by autoreception remained stable during the next $30 \mathrm{~min}$ of recording. The addition of BAPTA-AM (20 $\mu \mathrm{M})$ resulted in a marked decrease in the frequency of $\mathrm{m}$-MEPCs (Fig. $7 F$ ). The time course of this decrease was similar to that of MEPCs measured at the neuron-myocyte contacts described in the above. However, the magnitude of the effect was lower: the frequency at the end of the recording was 39\% of that before the treatment (Table 2$)$. This value was significantly $(p<0.05)$ higher than the final frequency found in BAPTA-treated neuronmyocyte contacts. Thus, BAPTA-AM inhibited spontaneous ACh release from myocytes and neurons to different extents. This difference may be accounted in part by the difference in the extent of BAPTA-induced reduction in $\left[\mathrm{Ca}^{2+}\right]_{i}$. In contrast to the results from neurons and myocytes, similar bath application of BAPTA-AM to fibroblasts injected with $\mathrm{ACh}$ did not change the frequency of the f-MEPCs detected by a myocyte manipulated into contact with the fibroblast prior to the BAPTAAM application (Fig. 7E, Table 2), although the Fura-2 imaging study described above had shown that such BAPTA-AM treatment induced a similar reduction in the cytoplasmic $\mathrm{Ca}^{2+}$ level as that in the myocyte.

\section{Effects of protein kinase $C$ activation}

Activation of protein kinase $\mathrm{C}$ (PKC) is known to elevate both spontaneous and nerve-evoked transmitter release at neuromuscular synapses (Publicover, 1985; Haimann et al., 1987) and central synapses (Finch and Jackson, 1990; Parfitt and Madison, 1993). In the present study, we tested whether such modulation of secretion by PKC also occurs in the non-neuronal cells. The phorbol ester PDBu was used to activate PKC. At neuron-myocyte contacts, bath-application of $1 \mu \mathrm{M}$ PDBu resulted in an increase in the MEPC frequency within minutes after application. The frequency $30 \mathrm{~min}$ after PDBu addition was severalfold higher than that prior to the drug application (Fig. 8A, Table 2). Similar bath application of PDBu also caused an increase of the frequency of m-MEPCs in ACh-loaded myocytes. After $30 \mathrm{~min}$ of treatment, the frequency was about twofold higher than that recorded before drug application (Fig. $8 \mathrm{C}$, Table 2 ). The magnitude of this effect was smaller $(p<0.05)$ than that seen at neuron-myocyte contacts. In sharp contrast to its effects on neurons and myocytes, a similar concentration of PDBu did not 

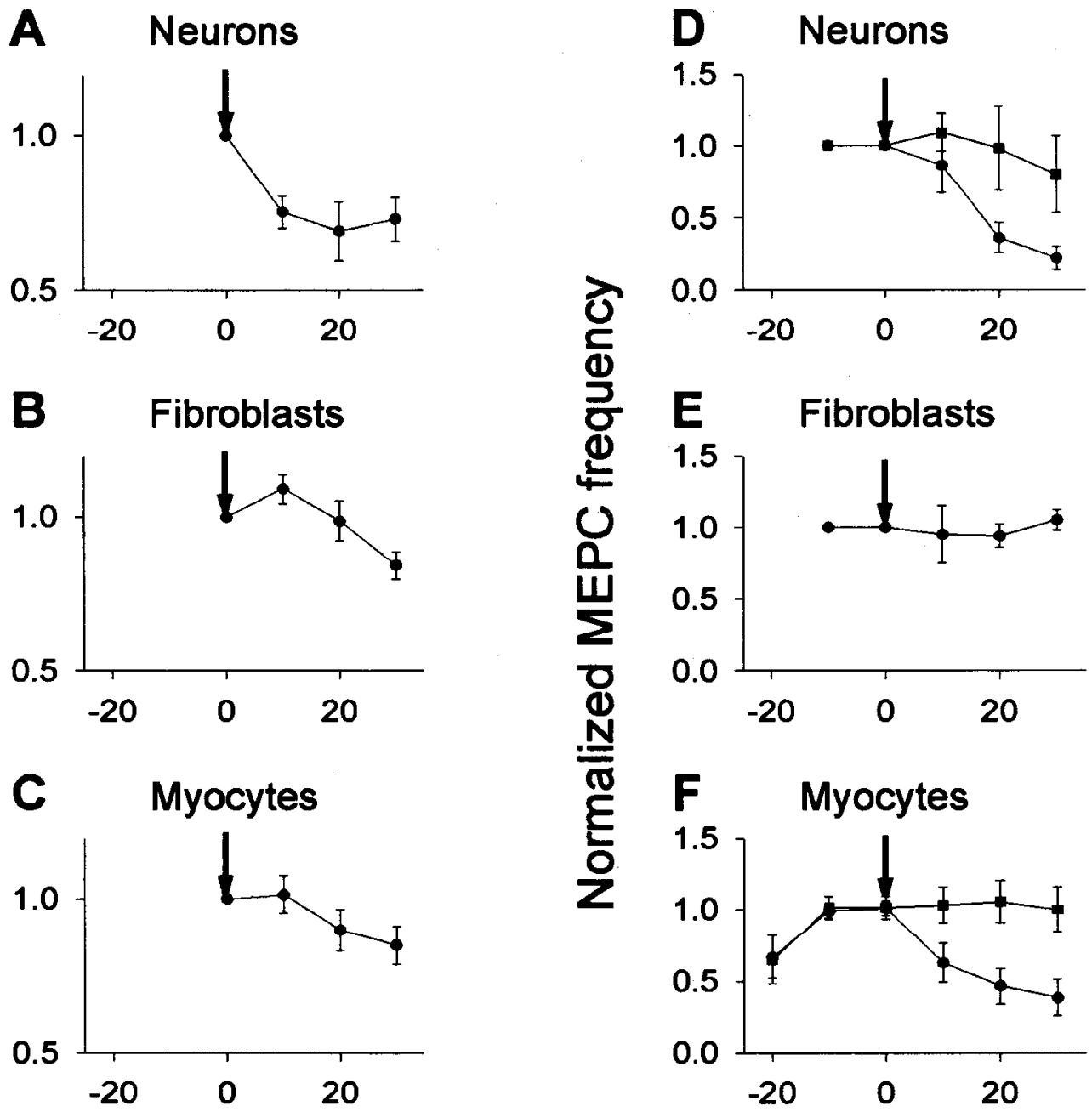

\section{Time $(\min )$}

Figure 7. Effects of the calcium chelator BAPTA-AM on intracellular $\mathrm{Ca}^{2+}$ and MEPCs frequency. On the left, the graphs depict the intracellular $\mathrm{Ca}^{2+}$ concentration $\left(\left[\mathrm{Ca}^{2+}\right]_{i}\right)$ measured with Fura-2 fluorescence ratio imaging at neuronal soma $(A)$, fibroblasts $(B)$, and myocytes $(C)$, before and

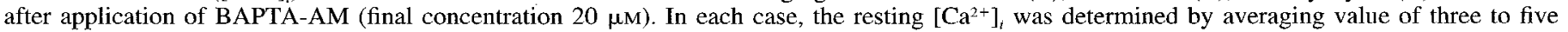
measurements taken during a 10-20 min control period prior to the BAPTA-AM addition. Only cells with stable resting [Ca $\left.{ }^{2+}\right]_{i}$ were considered. Calcium concentrations were normalized to the resting averaged $\left[\mathrm{Ca}^{2+}\right]_{i}$. Each data point is the mean normalized $\left[\mathrm{Ca}{ }^{2+}\right]_{i} \pm \mathrm{SEM}$ of $6-16$ cells. Addition of BAPTA-AM (arrow) caused a significant decrease of $\left[\mathrm{Ca}^{2+}\right]_{i}$ in all threc cell types. The decreases in fibroblasts and myocytes were comparable but smaller than the decrease in neurons. Graphs on the right show the average frequency of ACh secretion ( \pm SEM, $n=5-8)$ in the three cell types before and after addition of BAPTA-AM (arrows). The values were normalized to that cell's own control period ( -10 to 0 min for neurons and fibroblasts, and -20 to 0 min for myocytes) before averaging. At newly formed synapses $(D)$, and in fibroblasts $(E)$, BAPTA-AM was added to the bath after a $10 \mathrm{~min}$ period of control recording. In the case of myocytes $(F)$, the drug was applied after 30 min, when the MEPC frequency and amplitude had reached their plateau. After BAPTA-AM addition, the frequency of MEPCs occurrence in newly formed synapses $(D)$ and myocytes $(F)$ decreased (circles), whereas in untreated cells the frequency remained stable (squares). In fibroblasts, however, although BAPTA-AM did reduce $\left[\mathrm{Ca}^{2+}\right]_{i}(B)$ it did not alter the frequency of spontaneous secretion $(E)$. For clarity, the frequency in untreated fibroblasts is omitted. The magnitudes of the BAPTA-AM effect on the MEPCs frequency in the three cell types are given in Table 2.

produce any significant change in the frequency of spontaneous ACh secretion from the fibroblasts (Fig. $8 B$, Table 2).

\section{Discussion}

Previous biochemical and morphological studies have provided evidence that quantal transmitter secretion from presynaptic nerve terminals reflects exocytosis of transmitter-containing vesicles. The molecular basis underlying excitation-secretion coupling, however, has been explored only recently, as a result of successful identification of a number of proteins associated with synaptic vesicles and neuronal plasma membranes (reviewed in
Bennett and Scheller, 1993; Kelly, 1993; Walch-Solinema et al., 1993). Studies of constitutive secretion and membrane traffic in yeast and cell-free systems have shown that homologous proteins similar to presynaptic proteins are involved in membrane trafficking in neuronal and nonsecretory cells (Bennett and Scheller, 1993), suggesting that exocytosis of synaptic vesicles may involve fusion mechanisms similar to that in constitutive membrane trafficking in all eukaryotic cells. Studies of the recycling of synaptic vesicle membrane at presynaptic nerve terminals also suggest that synaptic vesicles may originate from the endocytic recycling pathway found in all eukaryotic cells. 
Table 2. Modulation of spontaneous yuantal ACh secretion by BAPTA-AM and PDBu

\begin{tabular}{lll} 
& BAPTA-AM & PDBu \\
\hline Neurons & $0.22 \pm 0.08^{*}(5)$ & $4.95 \pm 1.73^{*}(5)$ \\
Fibroblasts & $1.05 \pm 0.07(6)$ & $0.86 \pm 0.21 \quad(6)$ \\
Myocytes & $0.39 \pm 0.13^{*}(5)$ & $2.29 \pm 0.63^{*}(8)$
\end{tabular}

The values show the mean MEPC frequency ( \pm SEM) after 30 min of treatment with BAPTA-AM or PDBu, normalized for each cell before averaging to the frequency prior to drug treatment (see Fig. 7). Statistics compare the frequency in a given treated cell type to the frequency observed in untreated cells after the same duration of recording; *, $p<0.05$ (Mann-Whitney test).

The existence of exocytosis mechanisms in non-neuronal cells similar to those used in neuronal transmitter secretion is further supported by recent findings that both cultured myocytes (Dan and Poo, 1992) and fibroblasts (Alder et al., 1993) exhibit spontaneous quantal ACh secretion when exogenous ACh is loaded into the cells. The present study, in which a Xenopus myocyte was used as a detector for $\mathrm{ACh}$, provides a more detailed comparison of the quantal $\mathrm{ACh}$ secretion from the non-neuronal cells with that from cultured spinal neurons. Our results show that despite striking similarity in the quantal $\mathrm{ACh}$ secretion from all three cell types, there are distinct differences in the kinctics of secretion, the sensitivity to the intracellular $\mathrm{Ca}^{2+}$ concentration and to protein kinase $C$ activation.

Frequency. The frequency of MEPCs was higher for neurons than in fibroblasts and myocytes. It has been shown previously that isolated neurons exhibit very little spontaneous quantal $\mathrm{ACh}$ secretion, and marked increase in the frequency of secretion can be induced by specific contact with a myocyte (Xie and Poo, 1986; Sun and Poo, 1987). These results indicate that spontaneous ACh release is inhibited in isolated neurons and that the inhibition is reduced upon contact with the postsynaptic cell, possibly as a result of increased intraterminal $\mathrm{Ca}^{2+}$ (Dai and Peng, 1993). Synaptotagmin, which has been proposed to act as a $\mathrm{Ca}^{2+}$-sensitive inhibitor of transmitter secretion, may play an active role in this phenomenon (Popov and Poo, 1993). Such an inhibitory mechanism is probably unique to neurons and need not exist in non-neuronal cells. Indeed, as shown by Dan and Poo (1992) and by the result of the two-myocytes experiments in the present study, myocytes spontaneous secretion occurs in the absence of contact with other cells and was not potentiated by the contact with a second myocyte. Spontaneous release of ACh quanta through the constitutive secretion pathway in the absence of any cell contact was also found in fibroblasts incubated briefly with ACh-containing solution (Alder et al., 1993). The lower frequency of secretion in myocytes than in fibroblasts may reflect a difference in the rate of constitutive membrane recycling, since the endocytic recycling activity, as shown by staining of the cells with endocytic markers FM1-43 or FITCdextran, was found to be lower in myocytes than in fibroblasts (S. Popov, unpublished observation).

Amplitude. The median amplitude of $\mathrm{f}-\mathrm{MEPCs}$ and $\mathrm{m}$-MEPCs was smaller than that of neuronal MEPCs. The difference disappeared, however, when the time integrals of current transients were measured for all three cell types, indicating the total charge movement induced in the myocyte by the quantal ACh packets were similar in all three cell types. Thus, the lower amplitude of $\mathrm{f}-$ and $\mathrm{m}-\mathrm{MEPCs}$ probably reflects slower time course of the secretion and reception of the ACh packet in the two non-neuronal cells. The amplitude distribution of MEPCs were found to

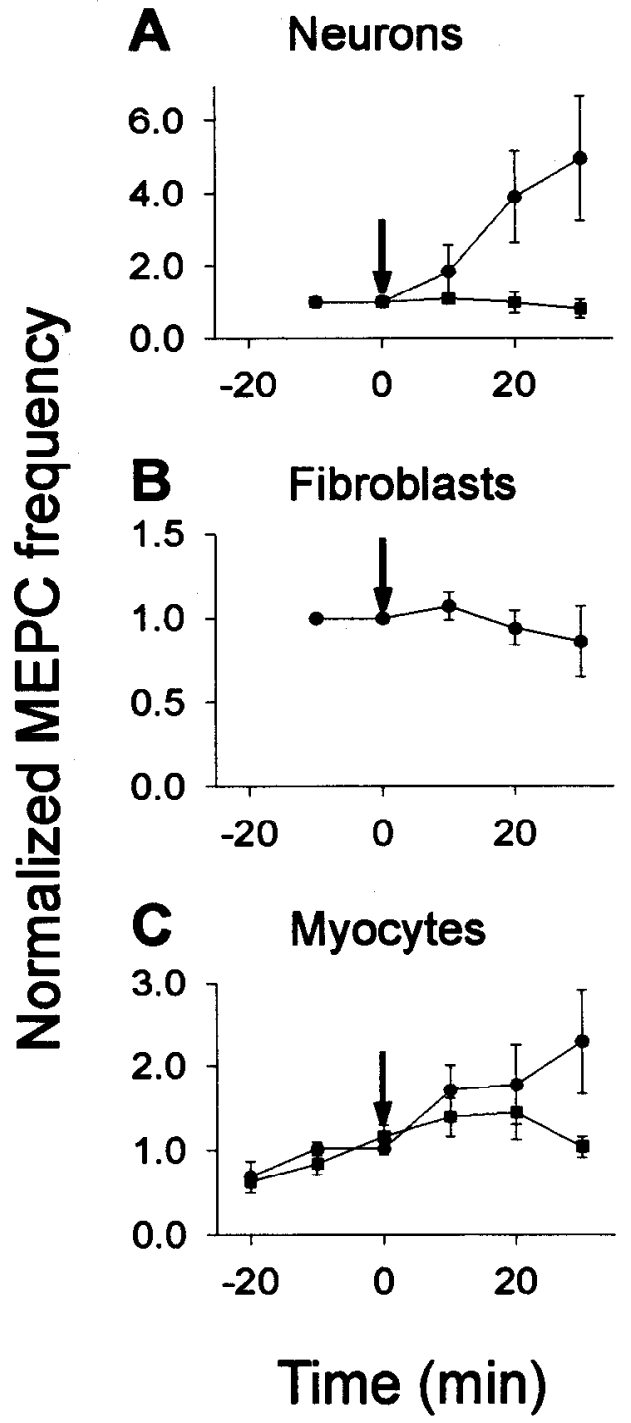

Figure 8. Modulation of spontaneous ACh quantal secretion by the phorbol ester PDBu. The same protocol as that described for modulation by BAPTA-AM was used (see Fig. $7 D-F)$. PDBu $(1 \mu \mathrm{M})$ was added to the bath at the time marked by the arrow. The drug increased the frequency of spontaneous $\mathrm{ACh}$ secretion events from developing neurons $(A)$ and myocytes $(C)$, but not from fibroblasts $(B)$. The magnitude of this effect after 30 min of treatment with PDBu is detailed in Table 2.

be similarly skewed toward smaller amplitudes for all three cell types. For developing Xenopus spinal neurons, it has been shown that skewed distribution of MEPCs was most likely due to the differences in the size of $\mathrm{ACh}$ packets in the neurons, rather than the variation of myocyte ACh sensitivity or density of AChEs (Evers et al., 1989). The striking similarity of the size and distribution of neuronal MEPCs with that of quantal secretion in non-neuronal cells supports the notion that synaptic vesicles in developing neurons are derived from a similar population of vesicles used for constitutive secretion in non-neuronal cells.

Our present results also suggest the existence of similar capacity for vesicular packaging of $\mathrm{ACh}$ in embryonic spinal neurons, fibroblasts, and myocytes. It is possible that a vesicular $\mathrm{ACh}$ transporter with functional characteristics similar to that in cholinergic synaptic vesicles is present in the vesicles of the constitutive/recycling pathway in myocyte and fibroblasts. Al- 
ternatively, ACh molecules were accumulated into vesicles by a nonspecific mechanism in all three cell types. The skewed amplitude distribution could reflect either different amounts of ACh accumulated in the vesicles of similar size or the same concentration of $\mathrm{ACh}$ accumulated in vesicles of different sizes. The maturation of the quantal $\mathrm{ACh}$ packets at neuromuscular junctions, as shown by the appearance of normal ("bell-shaped") distribution of MEPCs, might reflect either the acquisition of a neuron-specific $\mathrm{ACh}$ transporter by the synaptic vesicle or a selective use of vesicles of defined sizes, or both.

Time course. MEPCs in fibroblasts and myocytes had a slower time course than did neuronal MEPCs. The most likely explanation for this resides in the particular geometry of the neuronmyocyte contact, where close membrane--membrane apposition (with a gap $<10 \mathrm{~nm}$ ) was observed during the initial phase of synaptogenesis (Buchanan et al., 1989). This close apposition may shorten the time required for achicving maximal activation of the myocyte surface, resulting in faster rising rate of the synaptic currents. In contrast, MEPCs generated within the site of contact between the two myocytes did not have rise times shorter than those generated outside of the contact (see Fig. 2), suggesting that specific interaction of components of the growth cone membrane with the myocyte surface is required to shorten the rise time. Specific membrane apposition and flattening could also result in a more rapid diffusion of $\mathrm{ACh}$ from the release site, thus accounting for the faster decay of MEPCs. Such specific membrane interactions between neuron and myocyte must occur immediately following neuron-myocyte contact, since even early MEPCs, recorded within a few minutes of contact, had fast rising and decaying rates.

The structure of neuron-myocyte contacts appears not to be the only origin for the faster time course of neuronal MEPCs, however. The results obtained by simulating MEPCs with ion tophoretic $\mathrm{ACh}$ pulses indicate that the speed of $\mathrm{ACh}$ release may actually be higher in neurons than in fibroblasts and myocytes. In addition, about $10 \%$ of the spontaneous currents in nonneuronal cells had atypical shapes, with one or more notches on their rising and/or decaying phases. Similar atypical MEPCs were also found at neuron-myocyte contacts, but their time course was usually not as slow and their incidence was lower. In accordance with results obtained at adult neuromuscular junction (Vautrin and Kriehel, 1991) and at the Torpedo electric organ (Girod et al., 1993a), the present data indicate that atypical MEPCs resulted from irregular release of $\mathrm{ACh}$ from the cells, which is more likely to occur in the non-neuronal cells.

Fusion of secretory granules is thought to be initiated by the formation of a small fusion pore linking the lumen of the docked vesicle to extracellular space. The molecular nature of the fusion pore remains unknown, but it is generally accepted that for the fusion to occur a protein scaffold is needed to bring the vesicle membrane into close proximity with the plasma membrane (see for reviews, Almer and Tse, 1990; Monck and Fernandez, 1994). In fast synapses, the opening of the fusion pore has been proposed to correspond to the opening of a channel (Almers and Tse, 1990), possibly formed by synaptophysin (Thomas et al., 1988 ) or by the mediatophorc, a proteolipid isolated from the nerve terminal membranes of the Torpedo electric organ (Israel and Dunant, 1993). The difference in the secretion kinetics reported here may reflect the presence of a fusogenic protein specifically associated with synaptic vesicles and/or neuronal plasma membrane. The protein(s) may accelerate the speed with which the transmitter is discharged from neurons and limit the extent of the flickering of the fusion pore (see Monck and Fernandez, 1994), thereby decreasing the incidence of irregular discharges of transmitter. Faster transmitter secretion and rapid postsynaptic activation may represent aspects of neuronal differentiation necessary to achieve fast and reliable signaling in the nervous system.

$\mathrm{Ca}^{2+}$ sensitivity. The hallmark of neuronal $\mathrm{ACh}$ secretion is its sensitivity to the $\mathrm{Ca}^{21}$ concentration in the nerve terminal. Procedures known to elevate $\left[\mathrm{Ca}^{2+}\right]_{i}$ potentiate spontaneous transmitter secretion from embryonic neurons (Tabti and Poo, 1990). In addition, quantal ACh release from ACh-loaded myocytes was found to be increased after elevating $\left[\mathrm{Ca}^{2+}\right]_{i}$ by treatments that release $\mathrm{Ca}^{2+}$ from internal stores or by repetitive membrane depolarization (Dan and Poo, 1992). In the present study, we found that ionomycin increased the frequency of spontaneous quantal $\mathrm{ACh}$ secretion from fibroblasts, indicating that fibroblast sccretion is also scnsitive to a rise in the cytosolic $\mathrm{Ca}^{2+}$ concentration. However, the increase in fibroblast secretion was much smaller than that seen in neurons similarly treated with ionomycin. We further examined the sensitivity to $\mathrm{Ca}^{2+}$ of the secretory machinery in the three cell types by reducing cytoplasmic $\mathrm{Ca}^{2+}$ concentration with a membrane permeant $\mathrm{Ca}^{2+}$ chelator, BAPTA-AM. The chelator reduced the frequency of spontaneous release from both developing neurons and myocytes, but was ineffective in fibroblasts. The difference was apparently not due to a failure of BAPTA in reducing $\left[\mathrm{Ca}^{2+}\right]_{t}$ in fibroblasts, as indicated by the results from direct fura- 2 measurement of $\left[\mathrm{Ca}^{2+}\right]_{i}$. Thus, fibroblast secretion is affected only by large elevations in $\left[\mathrm{Ca}^{2+}\right]_{i}$, as induced by ionomycin, but is unaffected when $\left[\mathrm{Ca}^{2+}\right]_{i}$ is reduced from the resting level. In contrast, either an increase or decrease in $\left[\mathrm{Ca}^{2+}\right]_{i}$ modulates secretion from both myocytes and neurons. This indicates that secretion from these cells has a greater sensitivity to $\mathrm{Ca}^{2+}$ in comparison to fibroblast secretion. A previous study has also shown that $\mathrm{Ca}^{2+}$-dependent release of $\mathrm{ACh}$ from $\mathrm{ACh}$-loaded myocytes could be evoked by step depolarization of the myocyte membrane, but the excitation-secretion coupling was found to be much weaker than in neurons (Dan and Poo, 1992). Taken together, these results suggest that secretory machinery common to various cell types has become specialized in neurons to respond to fine changes in $\mathrm{Ca}^{2+}$.

Regulation by $P K C$. Activation of $\mathrm{PKC}$ by $\mathrm{PDBu}$ was effective in elevating the frequency of MEPCs in both myocyte and developing neurons, but not in fibroblasts. The effect of phorbol esters in enhancing spontaneous as well as evoked transmitter secretion from presynaptic nerve terminals has been shown previously at neuromuscular junctions (Publicover, 1985; Haimann et al., 1987) and central synapses (Finch and Jackson, 1990; Parfitt and Madison, 1993). The precise locus of PKC action at nerve terminals is unknown, although in hippocampal neurons blockade of voltage-dependent calcium channels with cadmium attenuated the phorbol ester-induced increase in spontaneous quantal secretion (Parfitt and Madison, 1993). The absence of phorbol ester effect in fibroblasts may be related to the lack of voltage-dependent calcium channel in these cells. In the hippocampus phosphorylation of synapsin I (Browning and Dudeck, 1992) and of GAP-43 (Dekker et al., 1989) was increased during $\mathrm{PKC}$ activation. If $\mathrm{PKC}$ exert its modulatory effect on $\mathrm{ACh}$ release through phosphorylation of specific proteins associated with the synaptic vesicles, then myocytes, but not fibroblasts, must have acquired similar proteins as those in neurons, since there was increased sensitivity to $\mathrm{Ca}^{2+}$ and $\mathrm{PKC}$ in both myo- 
cytes and neurons. Whether there is any relationship between this sensitivity and the appearance of membrane excitability remains to be further studied.

The spontaneous neuronal ACh secretion examined in the present study occurs at the early stage of synapse formation between nerve and muscle cells. The appearance of a defined, "bell-shaped" quantal size and morphological specializations of pre- and postsynaptic cell take many days or even weeks to complete (see review, Hall and Sanes, 1993). The similarity of quantal ACh secretion between the developing neurons and two non-neuronal cells supports the notion that presynaptic transmitter secretion pathway is ontogenetically related to the constitutive secretory pathway present in all cell types, and the differences, on the other hand, suggests the appearance of additional neuron-specific component(s) during neuronal differentiation.

\section{References}

Alder J, Popov S, Girod R, Poo M-m (1993) Calcium-dependent quantal secretion of neurotransmitter from fibroblasts. Soc Neurosci Abstr 19:611.

Almers W, Tse FW (1990) Transmitter release from synapses: does a preassembled fusion pore initiate exocytosis. Neuron 4:813-818.

Anderson MJ, Cohen MW, Zorychta E (1977) Effects of innervation on the distribution of acetylcholine receptors on cultured muscle cells. J Physiol (Lond) 268:731-756.

Bennett MK, Scheller RH (1993) The molecular machinery for secretion is conserved from yeast to neurons. Proc Natl Acad Sci USA 90:2559-2563.

Browning MD, Dudek EM (1992) Activators of protein kinase C increase the phosphorylation of the synapsins at sites phosphorylated by cAMP-dependent and $\mathrm{Ca}^{2+} / \mathrm{calmodulin}$-dependent protein kinase in the rat hippocampal slice. Synapsc 10:62-70.

Buchanan J, Sun Y-a, Poo M-m (1989) Studies of nerve-muscle interactions in Xenopus cell culture: morphology of early functional contacts. J Neurosci 9:1540-1554.

Chow I, Poo M-m (1985) Release of acetylcholine from embryonic neurons upon contact with the muscle cell. J Neurosci 5:1076-1082.

Dai $Z$, Peng HB (1993) Elevation in presynaptic $\mathrm{Ca}^{2+}$ level accompanying initial nerve-muscle contact in tissue culture. Neuron 10: $827-837$.

Dan Y, Poo M-m (1992) Quantal transmitter secretion from myocytes loaded with acetylcholine. Nature 359:733-736.

Dekker I.V, DeGraan P, Versteeg DH, Oestreicher AB, Gispen WH (1989) Phosphorylation of B-50 (GAP43) is correlated with neurotransmitter release in rat hippocampal slices. J Neurochem 52:4-30.

Del Castillo J, Katz B (1954) Quantal components of the end-plate potential. J Physiol (Lond) 124:560-573.

Dunant Y, Muller D (1986) Quantal release of acetylcholine evoked by focal depolarization at the Torpedo nerve-electroplaque junction. J Physiol (Lond) 379:461-478.

Evers J, Laser M, Sun Y-a, Xie Z-p, Poo M-m (1989) Studies of nerve-muscle interactions in Xenopus cell culture: analysis of early synaptic currents. J Neurosci 9:1523-1539.

Finch DM, Jackson MB (1990) Presynaptic enhancement of synaptic transmission in hippocampal cell cultures by phorbol esters. Brain Res 518:269-273.

Frank E, Fischbach GD (1979) Farly events in neuromuscular junction formation in vitro. Induction of acetylcholine receptor clusters in the postsynaptic membrane and morphology of newly formed nervemuscle synapses. J Cell Biol 83:143 158.

Girod R, Eder-Colli L, Medilanski J, Dunant Y, Tabti N, Poo M-m (1992) Pulsatile release of acetylcholine by isolated nerve terminals (synaptosomes). J Physiol (Lond) 450:325-340.

Girod R, Correges P, Jacquet J, Dunant Y (1993a) Space and time characteristics of transmitter release at the nerve-electroplaque junction of 'Torpedo. J Physiol (Lond) 471:129-157.

Girod R, Alder J, Popov S, Poo M-m (1993b) Comparison of quantal
ACh secretion from myocytes, fibroblasts and neurons. Soc Neurosci Abstr 19:612.

Graessmann A, Graessmann M, Mueller C (1980) Microinjection of early SV 40 DNA fragments and $\mathrm{T}$ antigen. Methods Enzymol 65: $816-825$

Grynkiewicz G, Poenie M, Tsien RY (1985) A new generation of $\mathrm{Ca}^{2+}$ indicators with greatly improved fluorescence properties. J Biol Chem 260:3440-3450.

Haimann C, Meldolesi J, Cecarelli B (1987) The phorbol ester, 12- $O$ tetradecanoyl-phorbol-13-acetate, enhances the evoked quanta release of acetylcholine at the frog neuromuscular junction. Pfluegers Arch 408:27-31.

Hall ZW, Sanes JR (1993) Synaptic Structure and development: the neuromuscular junction. Cell/Neuron [Suppl] 72/10:99-121.

Hamill OP, Marty A, Neher A, Sakmann B, Sigworth FJ (1981) Improved patch-clamp techniques for high-resolution current recording from cells and cell-free membrane patches. Pfluegers Arch 391:85100 .

Israël M, Dunant Y (1993) Acetylcholine release, from molecules to function. Prog Rrain Res 98:219-233.

Kelly RB (1993) Storage and release of neurotransmitter. Cell/Neuron [Suppl] 72/10:43-53.

Kidokoro Y (1984) Two types of miniature endplate potentials in Xen opus nerve-muscle cultures. Neurosci Res 1:157-170.

Kuffler SW, Yoshikami DJ (1975) The number of transmitter molecules in a quantum: an estinate from iontophoretic application of acelylcholine at the neuromuscular synapse. J Physiol (Lond) 251:465-482.

Land BR, Salpeter EE, Salpeter MM (1981) Kinetic parameters for acetylcholine interaction in intact neuromuscular junction. Proc Natl Acad Sci USA 78:7200-7204.

Monck JR, Fernandez JM (1994) The exocytotic fusion pore and neurotransmitter release. Neuron 12:707-716.

Muniak CG, Kriebel ME, Carlson CG (1982) Changes in MEPP and FPP amplitude distributions in the mouse diaphragm during synapse formation and degeneration. Dev Brain Res 5:123-138.

Nieuwkoop PD, Faber J (1967) Normal table of Xenopus laevis (Daudin), 2d ed. Amsterdam: North Holland.

Parfitt KD, Madison DV (1993) Phorbol esters enhance synaptic transmission by a presynaptic, calcium-dependent mechanism in rat hippocimpus. J Physiol (Lond) 471:245-268.

Poo M-m (1982) Rapid lateral diffusion of functional ACh receptors in embryonic muscle cell membrane. Nature 295:332-334.

Popov SV, Poo M-m (1993) Synaptotagmin: a calcium-sensitive inhibitor of exocytosis? Cell 73:1247-1249.

Publicover SJ (1985) Stimulation of spontaneous transmitter release by the phorbol ester, 12-O-tetradecanoylphorbol-13-acetate, an activator of protein kinase C. Brain Res 333:185-187.

Spitzer NC, Lamborghini JC (1976) The development of the action potential mechanism of amphibian neurons isolated in culture. Proc Natl Acad Sci USA 73:1641-1645.

Sun, Y-a, Poo, M-m (1987) Evoked release of acetylcholine from the growing embryonic neuron. Proc Natl Acad Sci USA 84:2540-2544.

Tabti N, Poo M-m (1990) Spontaneous synaptic activity at developing neuromuscular junctions. Prog Brain Res 84:63-72.

Tabti N, Poo M-m (1991) Culturing spinal neurons and muscle cells from Xenopus embryos. In: Culturing nerve cells (Banker G, Goslin K, eds). Cambridge, MA: MTT Press.

Thomas L, Hartung K, Langosch D, Rehm H, Bamberg E, Franke WW, Betz H (1988) Identification of synaptophysin as a hexameric channel protein of the synaptic vesicle membrane. Science 242:10501053.

Tsien RY, Poenie M (1986) Fluorescence ratio imaging: a new window into intracellular ionic signaling. Trends Biochem Sci 11:450-455.

Vautrin J, Kriebel ME (1991) Characteristics of slow-miniature endplate currents show a subunit composition. Neuroscience 41:71-88.

Walch-Solimena C, Jahn R, Sudhof TC (1993) Neurotransmitter release. Curr Opin Neurobiol 3:329-336.

Xie Z, Poo M-m (1986) Initial events in the formation of neuromuscular synapse: rapid induction of acetylcholine release from embryonic neuron. Proc Natl Acad Sci USA 83:7069-7073.

Young SH, Poo M-m (1983) Spontaneous release of transmitter from growth cones of embryonic neurons. Nature 305:634-637. 